\title{
Filmes de família, cinema amador e a memória do mundo
}

////////////////// Consuelo Lins ${ }^{1}$

Thais Blank ${ }^{2}$

1. Professora da Escola de Comunicação da Universidade Federal do Rio de Janeiro, pesquisadora do Conselho Nacional de

Desenvolvimento Científico e Tecnológico e cineasta. Autora de $\mathrm{O}$ cinema de Eduardo Coutinho: televisão, cinema e vídeo (2004) e, em parceria com Cláudia Mesquita, de Filmar o real: sobre o documentário brasileiro contemporâneo (2007). E-mail: consuelolins@gmail.com

2. Montadora e doutoranda em comunicação pela ECO/UFRJ.

Desenvolve uma tese em torno dos filmes de família e sua apropriação pelo cinema. E-mail: thaisblank@gmail.com 


\section{Resumo}

A retomada de imagens amadoras e de registros familiares em filmes documentários se intensificou no decorrer das últimas duas décadas. Esse artigo discute as noções de cinema amador e familiar propostas pelo pesquisador Roger Odin, o gesto de apropriação e de deslocamento dessas imagens, bem como sua recontextualização, no cinema contemporâneo. Concentraremo-nos na obra do artista húngaro Péter Forgács, que desde os anos 1980 realiza instalações e documentários com imagens amadoras produzidas, em grande parte, por cinegrafistas judeus da Europa Central. Forgács cria nesses filmes uma trama complexa, em que a vida dos personagens e os rumos tomados por eles se confundem com o destino do mundo.

\section{Palavras-chave}

filme de família, apropriação, documentário

\section{Abstract}

The resumption of amateur images and home movies in documentaries has intensified over the past two decades. This article discusses the notions of amateur and family movies proposed by the theorist Roger Odin and the gesture of appropriation and displacement of these images, as well their recontextualization, in contemporary cinema. We focus our analysis on the work of the Hungarian artist Péter Forgács, who since 1980 makes installations and documentary films with amateur images, largely produced by Jews cameramen from Central. Forgács creates complex plots in his films, where the characters' life, the directions taken by them and the fate of the world entwine.

\section{Keywords}

home movies, appropriation, documentary 


\section{Documentário e filme de família}

Como transformar filmes de família que interessam apenas aos que neles estão envolvidos em imagens de uma memória comum, a ser compartilhada com um público mais amplo? Como fazer que a vida de personagens quaisquer se confunda com os destinos de uma época, dissolvendo as fronteiras entre as memórias pessoais e a "memória do mundo"?

Os filmes de família vêm ganhando nas últimas décadas cada vez mais atenção de cineastas ligados ao campo do documentário. Desde o final dos anos 80, momento em que a subjetividade se sedimentou como uma tendência forte do documentário, as imagens realizadas por câmeras amadoras têm sido incorporadas pelos documentaristas, com objetivos variados: narrar aspectos biográficos da vida do realizador; evocar trajetórias de personagens filmados por ele; interrogar o próprio material, identificando nele camadas menos visíveis de imagens e sentidos. Imagens perdidas, esquecidas, dispersas, arquivadas sem critério ou sem sentido ressurgem em filmes diversos. Rolos de película desprovidos de uma narrativa contínua e nos quais é possível encontrar uma festa de aniversário, depois de uma viagem de navio, e uma parada militar sem que se possa identificar as relações entre esses acontecimentos, a menos que tenhamos informações "extraimagem".

Em filmes como Tren de sombras: el espectro de le Thuit, do espanhol José Luis Guerin (1997), Mort à Vignole, do belga 
3. A noção de "filme palimpsesto"

foi desenvolvida por Sylvie Lindeperg em seu livro Les écrans de l'ombre: la Seconde Guerre mondiale dans le cinéma français (19441969). Nele, Lindeperg elabora um método de análise que intitula de "o cinema em ação”, no qual convida o pesquisador a entrar no interior da "caixa-preta" do cinema para refazer o processo de fabricação dos filmes.
Olivier Smolders (1998), The future is behind you, da americana Abigail Child (2004), Intimate stranger (1991), do americano A. Berliner, e em toda a obra do cineasta húngaro Péter Forgács, imagens domésticas são retomadas de formas distintas: não como documento do que aconteceu, tampouco como expressão de uma verdade familiar, mas como imagens capazes de nos fazer acessar novos pontos de vista sobre a memória e sobre a história, coletiva e individual. Ao longo desse texto, os filmes de Péter Forgács serão nossos exemplos privilegiados das questões teóricas apresentadas. Entre os cineastas citados acima, é ele quem faz da apropriação de imagens amadoras a marca mais evidente de todo o seu trabalho.

Para entendermos esse movimento de retomada de imagens domésticas na produção audiovisual atual, propomos, em primeiro lugar, investigarmos o que são essas imagens: de onde elas vêm, para que são feitas e a finalidade com que são produzidas antes de serem apropriadas por artistas e cineastas profissionais. Operamos com a noção de que os filmes de arquivo são como "palimpsestos": antigos manuscritos em pergaminho nos quais os copistas apagavam o texto original para escrever algo novo, procedimento que podia acontecer sucessivas vezes. Mas, apesar da raspagem, alguns caracteres das escritas anteriores ainda continuavam visíveis nos pergaminhos. Os "filmes palimpsestos" - noção elaborada pela pesquisadora francesa Sylvie Lindeperg ${ }^{3}$ - apresentam as marcas de sua construção e dos seus diferentes usos ao longo do tempo; uma imagem familiar, ainda que "ressignificada" e retirada do contexto, guarda consigo a marca da intimidade, e são essas marcas, essas diferenciações que propomos entender neste primeiro momento.

A apropriação, o deslocamento e a recontextualização de imagens já fabricadas expressam um gesto muito particular do cinema contemporâneo. Como lembra o pesquisador espanhol Josep M. Català, não se trata mais de sair em busca do arquivo para ilustrar um determinado acontecimento, como o documentarista clássico, mas de trabalhar diretamente com a memória visual (CATALÀ, 2007), montando, construindo, inventando novas memórias. São obras que libertam as imagens do universo doméstico e fazem que elas se integrem ao mundo, adquirindo 
em muitos casos uma dimensão política, nos termos de Jacques Rancière. Para o filósofo francês, agir politicamente é agir sobre "partilhas" dadas, seja no campo político, seja no campo da arte, seja no campo social. Nos filmes em questão aqui, os cineastas dissolvem as funções originais do material encontrado - filmes de família para serem vistos pela família, visando o fortalecimento dos laços e a continuidade do grupo — para obter novas configurações sensíveis. As imagens deixam de estar a serviço da memória familiar para se tornar testemunhas da história, compartilhadas, produzindo experiências inéditas para um público de anônimos.

\section{Filme de família como 'objeto teórico’}

É somente a partir de meados dos anos 90 que o filme de família se institucionaliza efetivamente como uma vertente importante da pesquisa acadêmica. Uma coletânea de artigos, reunindo diferentes autores sob o título de Le film de famille, usage privé, usage public, organizada pelo pesquisador Roger Odin, faz do filme de família um objeto de pesquisa digno de atenção especial dentro do campo do cinema. Também na década de 90, a pesquisadora americana Patricia Zimmermann, da Universidade de Ithaca, publica sua primeira pesquisa sobre os filmes de família, Reel families: a social history of amateur film, que mapeia a história do cinema não profissional atravessando quase todo o século XX. Para delimitarmos o nosso campo de trabalho e para entendermos o que caracteriza um registro audiovisual como filme doméstico, partiremos de algumas noções propostas por esses pesquisadores e, principalmente, pelos autores que compõem a coletânea de Roger Odin.

É importante ressaltar que neste artigo temos como interesse principal os filmes amadores e familiares realizados em película. Na década de 1980, o advento do vídeo transformaria os modos de produção e de exibição de imagens familiares, e Zimmermann e Odin estiveram atentos às mudanças provocadas pela nova

4. Artigo publicado em Cadernos de Antropologia e Imagem, n. 17, Rio de Janeiro, 1995. tecnologia. Em artigo intitulado "As produções familiares de cinema e vídeo na era do vídeo e da televisão" $(1995)^{4}$, Roger Odin analisa as transformações acarretadas pela entrada definitiva das imagens familiares no espaço público - primeiramente, na televisão e, mais 
tarde, na internet. Algumas das questões que levantamos ao longo do texto devem, portanto, ser atualizadas quando pensadas em relação à produção de imagens familiares em vídeo e em digital.

Roger Odin afirma que os filmes de família foram esquecidos pelo movimento de reflexão sobre o cinema que se desenvolveu depois dos anos 1960 e estariam ausentes da história, das teorias e das enciclopédias cinematográficas. Para o autor, além da dominação incontestável dos filmes de ficção no campo de pesquisa cinematográfico, os filmes domésticos são geralmente desvalorizados por sua "cotidianidade", por serem praticados como simples distração por pessoas que ignoram todas as regras cinematográficas, e aparecem, muitas vezes, como fúteis e fundamentalmente tediosos (ODIN, 1995).

Para Patricia Zimmermann, as imagens amadoras costumam ocupar no imaginário popular o lugar do "malfeito", do "não profissional" e do desnecessário. A autora explica ainda que os filmes familiares e amadores tiveram, desde 1895, uma trajetória histórica e comercial paralela à do cinema comercial e, apesar do desenvolvimento e do uso contínuo da tecnologia "caseira" desde a década de 1920, os filmes domésticos têm sido frequentemente percebidos como passatempos irrelevantes e descartados como insignificantes subprodutos do consumo tecnológico (ZIMMERMANN, 2008, p. 1).

No entanto, na última década, temos presenciado um maior interesse em preservar essas imagens, não só por parte de pesquisadores e de cineastas mas também dos próprios arquivos. No Brasil, um bom exemplo é o da Cinemateca Brasileira de São Paulo, que tem constituído um grande acervo de imagens amadoras e familiares - constantemente consultado e utilizado por artistas brasileiros.

Podemos apontar como uma das causas para o interesse crescente por imagens domésticas o entendimento de que filmagens da privacidade são mais do que simples registros da trivial vida familiar. São também "documentos históricos". No artigo "Le film de famille comme document historique", Susan 
Aasman defende que os filmes domésticos se inscrevem em uma tradição que é anterior ao próprio cinema: a dos retratos de família pintados como um gênero, que aparecem na Renascença com a ascensão da burguesia. Em seu estudo L'enfant et la vie familiale sous l'Ancien Régime, o historiador Philippe Ariès mostra de que forma esse tipo de pintura pode ser vista como um "documento histórico", como testemunha de uma mudança de atitudes na esfera da infância e da vida privada. Para Aasman, a substituição dos retratos pintados pela fotografia - e, mais tarde, sendo possível também capturar esses momentos da família pelo cinema - não representou apenas uma troca de técnicas mas também uma verdadeira revolução social. Os filmes domésticos seriam, assim, testemunhas e agentes dessa revolução.

Em “Aux origines du cinéma: le film de famille", Eric de Kuyper afirma que os filmes domésticos mudam de status quando são depositados em um arquivo público. De suvenires familiares destinados ao uso dos íntimos se transformam em fragmentos da memória coletiva, testemunhas de um tempo que não conhecemos, do cotidiano de uma época e de outras formas de vida. Para o autor, além de interesse histórico, os filmes amadores possuem força e autenticidade refrescantes. Em meio à saturação da produção audiovisual, tomamos consciência de uma certa "força original" das imagens amadoras, como se na sua autenticidade e no seu despojamento elas guardassem uma dimensão perdida do cinema (KUYPER, 1995).

\section{Cinema amador e familiar: definições}

Os filmes amadores e familiares representam a face privada do cinema; o seu desenvolvimento está ligado à ampliação e à diversificação das formas de lazer para além das salas de teatros e das feiras de atrações. A disseminação da produção amadora se deu principalmente a partir da década de 1920, quando equipamentos mais simples de filmagem e projeção, diretamente voltados para o uso doméstico, foram lançados no mercado. Porém, desde sua origem, o cinema já apresentava um 
caráter privado. Em artigo intitulado "L'amateur: une figure de la modernité esthétique”, Laurence Allard defende a hipótese de que o curta-metragem Le repas du bébé (1895), realizado pelos irmãos Lumière, teria sido o primeiro filme de família da história. Para a autora, o interesse dos Lumière pelo cinema pode ter tido sua origem em um uso familiar da imagem em movimento, que serviria como substituto dos álbuns de fotografia.

O cinema não substituiu o instante fotográfico, mas o sonho de preservar a memória em movimento esteve presente desde os primórdios. Em 30 de dezembro de 1895, quando o cinematógrafo acabava de ser criado, o jornal francês La Poste publicou uma resenha sobre a nova invenção. Lida mais de cem anos depois, ela nos parece premonitória. Ainda muito cedo, seu autor foi capaz de perceber a potência democrática do cinema, que permitiria a perpetuação de múltiplas memórias.

Quando esses aparelhos estiverem livres ao público, quando todos puderem fotografar os entes queridos, não mais na sua forma imóvel, mas em seu movimento, em suas ações, em seus gestos familiares, a morte deixará de ser absoluta. E a história cotidiana, da nossa moral, dos nossos costumes, o movimento das nossas multidões passarão para a posteridade, não mais fixada, mas com a exatidão da vida (LA POSTE, 1895 apud ALLARD, 1999, p. 3-31).

O registro da história cotidiana, do movimento das multidões, encontrará lugar em dois “personagens” que surgem nesse momento inicial de desenvolvimento tecnológico do cinema. De um lado, os pais de família que, com a câmera em punho, acompanhavam o crescimento dos filhos, as viagens de férias, as confraternizações. De outro, o cineasta amador interessado em aprender a técnica cinematográfica e em reproduzir os padrões profissionais e que não se limitava em registrar a família.

A pesquisadora brasileira Lila Foster, que realizou uma investigação sobre a institucionalização do cinema amador no Brasil, mostra que as campanhas publicitárias destinadas a vender equipamentos não profissionais desenvolvidos na década de 1920, tinham como público-alvo o primeiro grupo de cineastas. Segundo 
Foster, "em todas as campanhas publicitárias, a família era o alvo principal para a produção de filmes de preservação da memória" (2010, p. 42). A autora apresenta diversos anúncios publicados na revista brasileira Cinearte durante esse período nos quais podemos observar a constante presença da família. Em 1928, a câmera Pathé Baby era vendida da seguinte forma pelos seus anunciantes:

\footnotetext{
Um acompanhamento interessante que deve fazer parte de sua bagagem é a MOTOCAMERA PATHE-BABY, que vos permite filmar sem mesmo conhecer photografia, os pitorescos aspectos que geralmente se apresentam no banho de mar, e que muitas recordações felizes ou risonhas vos proporcionarão passando os filmes em sua casa num projetor (apud FOSTER, 2010).
}

Foster mostra em sua pesquisa que, se as campanhas publicitárias eram destinadas ao cineasta familiar, as publicações e as colunas especializadas tinham como público-alvo os cineastas amadores. Geralmente voltadas para o aperfeiçoamento da técnica, para a difusão de novas tecnologias e para as discussões estéticas, as publicações especializadas faziam parte de uma rede de conhecimentos e relações na qual o cineasta amador deveria ser iniciado.

A distinção entre os cineastas amadores e os familiares é tema recorrente nos artigos de Roger Odin, para quem essas duas figuras, ainda que sejam frequentemente confundidas, possuem uma atitude radicalmente diferente diante da filmagem e das próprias imagens (ODIN, 1999). Segundo Odin, enquanto o cineasta amador declara querer fazer um cinema de qualidade, o cineasta familiar não pretende sequer fazer um filme. Para se tornar um cineasta amador, o cinegrafista precisa retirar de suas imagens a família, ou se retirar da família para produzir imagens dela. Se quiser reproduzir a estética profissional e fazer um filme "benfeito", o cineasta terá que se colocar de fora, se excluir. Precisará dirigir os integrantes, ajeitar a luz, encontrar o enquadramento adequado, deixar de ser um membro da família para se tornar um diretor.

Odin cita como exemplo o filme O amador (1979), de Kieslowski. O filme narra a trajetória de um cineasta familiar que pouco a pouco é tomado pelo desejo de "fazer cinema" e que por 
causa dessa troca de papéis perde a esposa e a filha. Em uma das cenas citadas por Odin, vemos o personagem filmar sua filha se balançando em uma cadeira. Quando a cadeira desmonta, o cinegrafista pede para a mulher não pegar o bebê e continua filmando. "E se ela cair de uma varanda, vai continuar filmando?", pergunta a esposa, com raiva. Para Odin, essa sequência define a distinção radical entre os cineastas familiares e os amadores, que, no fundo, sonham em ser profissionais: "filmar sua vida como cineasta é excluir a si mesmo da família, transformar a vida familiar em espetáculo" (ODIN, 1999, p. 52).

São, portanto, atitudes diferentes diante do mundo a ser filmado, mas em muitos casos elas se encontram em um mesmo indivíduo, em momentos diversos. Não são poucos os exemplos em que um cineasta familiar é também um amador em eventos que não dizem respeito à vida doméstica, problematizando essas definições e misturando essas atitudes na prática. De todo modo, partir dessas definições nos auxilia a identificar nas imagens aspectos particulares que, de outro modo, passariam despercebidos.

\section{Péter Forgács entre os filmes de família e as imagens amadoras}

Cineastas amadores e familiares produziram ao longo do tempo imagens de naturezas distintas, e podemos reconhecer essas diferenças quando essas imagens são reutilizadas em documentários contemporâneos. Mesmo nas ocasiões em que já não sabemos nada sobre os cinegrafistas, o desejo que os move, ou o gesto original, parece sobreviver nas imagens. Esse é o caso dos arquivos utilizados pelo húngaro Péter Forgács: o cineasta se baseia na reapropriação de filmagens amadoras e domésticas realizadas por cinegrafistas, em sua maioria judeus da Europa Central, entre os anos que antecederam a Segunda Guerra Mundial até a era comunista do pós-guerra. São imagens que mostram momentos da vida privada, como viagens de férias, casamentos e brincadeiras infantis, e que revelam acontecimentos importantes da época, como os campos de batalha da Guerra Civil Espanhola e a fuga de judeus para a Palestina. 
No filme O êxodo do Danúbio (1998), as imagens produzidas pelo capitão Nándor Andrásovits foram claramente feitas sob um sentido de urgência. $\mathrm{O}$ capitão do navio que transportava os judeus fugidos da Eslováquia para a Palestina não filma a viagem para incluir as imagens em sua coleção de suvenires familiares; ele parece perceber que está diante de um evento histórico. Já o filme Miss Universo, 1929 (2006) é montado em grande parte com as filmagens familiares de Marci Tenczer, que filmou ao longo da vida a prima Lisl Goldarbeiter, por quem era apaixonado. Em Miss Universo, a história da guerra europeia entra no filme pelas mãos de Forgács; essa narrativa não está contida nas imagens feitas por Tenczer.

Em El Perro Negro (2005), o cinegrafista Ernesto Noriega, que filmou as cenas de batalha durante a Guerra Civil Espanhola retomadas por Forgács ao longo do filme, conta que por sorte não teve que atirar em ninguém durante a guerra. Ele explica que, apesar de ter estado presente nos campos de batalha, estava sempre filmando e que, para isso, precisava ficar a pelo menos 700 metros das pessoas, distância muito longa para atirar. A fala de Noriega ilustra a diferença entre os cinegrafistas amadores e os familiares destacada por Roger Odin: o amador é um observador, se coloca de fora da cena para registrá-la; o cineasta familiar é antes de tudo um participante.

\section{O espectador dos filmes de família: entre identificação e voyeurismo}

Ser "participante" implica um tipo muito particular de interação entre a câmera e os filmados e que se traduz na estética das imagens. Ao contrário da câmera invisível dos filmes de ficção, reconhecemos o aparato, que é tratado como sujeito da ação tanto quanto os personagens filmados. Há um verdadeiro diálogo entre aqueles que se encontram diante e atrás do equipamento. Pelo fato de ser um integrante da família, o cinegrafista compartilha a 
5. Trata-se de um ritual que acontece cada vez menos, já que as imagens são vistas de maneira muito mais informal do que quando

eram necessários um projetor e a organização de uma efetiva "sessão". experiência vivida e recebe olhares, sorrisos, acenos que se dirigem diretamente para a lente. Nas projeções em família ${ }^{5}$, revisitam-se os "paraísos perdidos" da vida familiar (JOURNOT, 2011): o tempo em que o avô ainda estava vivo, a filha era uma graça de bebê ou a esposa era uma jovem linda. Roger Odin chama a atenção para a importância dos comentários durante as exibições: as imagens são acompanhadas pelo burburinho da plateia, que identifica, aponta, destaca personagens e acontecimentos. Durante a projeção, cada indivíduo da família dá a sua versão sobre o que as imagens significam. Mais do que espectadores, eles são personagens ativos, que atuam na criação coletiva da narrativa familiar (ODIN, 1995). Nesse sentido, a incoerência do filme importa pouco, já que a construção da coerência constitui a finalidade mesma da projeção.

É por esse motivo que Odin afirma que, para ser "bem-sucedido", um filme de família não deve ser "benfeito"; pelo contrário, ele deve possuir lacunas que permitam que cada um projete e recrie a sua própria narrativa memorial dos eventos mostrados. Quanto menos construído for, mais os membros da família poderão recriar juntos a história familiar e maior será a coesão do grupo. Para Odin, montar um filme de família é exercer poder sobre a narrativa familiar e bloquear a possibilidade de uma construção coletiva consensual. Odin vai ainda mais longe e afirma que a projeção de um material familiar montado pode causar um verdadeiro "mal-estar" na família, pois, depois de editadas, as imagens passam a se desenrolar sob um único ponto de vista, o do narrador, que não corresponde necessariamente à visão que outros envolvidos tiveram do evento.

Se, para Odin, os espectadores se tornam participantes, para Kuyper, eles são testemunhas de algo que aconteceu durante a filmagem. No jogo de afetos, olhares e sorrisos desencadeado entre o operador da câmera e os personagens filmados, um espectador posterior não é, na maior parte dos casos, levado em conta. Não é raro encontrar nesses filmes imagens que muitas vezes não foram feitas sequer para serem mostradas para além do círculo familiar. Para Kuyper, quando assistimos a essas imagens, somos apenas testemunhas de um evento vivido, testemunhas da cumplicidade, da felicidade e da intimidade familiar. Kuyper afirma que nos filmes 
6. As questões levantadas por Kuyper e Sierek nos parecem pertinentes quando pensamos em filmes de família feitos em película. Os novos modos de produção e de circulação das imagens familiares demandam uma revisão dos problemas identificados pelos autores. de família um outro tipo de identificação é colocada em cena: se nos filmes de ficção o espectador se identifica com a câmeraprojeção, nos filmes familiares, ele deve se identificar com o sujeito que está atrás da câmera, com quem é partilhada a comunicação da intimidade. Caso contrário, o espectador ficará excluído e se transformará em um verdadeiro voyeur (KUYPER, 1995).

O caráter por vezes voyeurístico das imagens familiares e o desejo de compartilhamento da intimidade permitem que Kuyper estabeleça uma relação entre os filmes de família e os filmes pornográficos. Para o autor, o cinema pornô e os filmes domésticos visam um uso interno e não espetacular e possuem em comum uma certa intimidade obscena: “olhares para a câmera que se fazem sem vergonha no prazer de dividir um segredo íntimo" (KUYPER, 1995, p. 18).

Mas o que acontece quando esses filmes são retirados de seu local de origem? Quando espectadores anônimos e desconhecidos se colocam diante de imagens tão íntimas? No artigo “'C'est beau, ici'. Se regarder voir dans le film de famille”, Karl Sierek se pergunta se o visionamento de imagens amadoras não envolveria problemas de cunho ético e questiona se nós temos o direito de ver imagens que não nos foram destinadas e de nos apropriarmos delas (SIEREK, 1995, p. 64). Para ele, o espectador dessas imagens é antes de tudo um intruso ${ }^{6}$.

Estranho, intruso, estrangeiro. Esses seriam bons adjetivos para qualificar os cineastas que se apropriam de imagens domésticas. Por possuírem um olhar de fora, mesmo quando falam de dentro, eles são capazes de descobrir novos sentidos nas imagens - que não eram previstos quando essas imagens eram destinadas apenas ao âmbito doméstico. Não é por acaso que o procedimento que marca os filmes de arquivo que utilizam imagens amadoras da intimidade é a montagem. Interditada na esfera familiar, ela se torna essencial para fazer que as imagens ganhem o mundo e estabeleçam com o espectador relações mais amplas e mais complexas do que o prazer voyeurístico de assistir à intimidade alheia. 


\section{Péter Forgács e a montagem da história}

Como escapar dos riscos apontados por Odin (identificação) e Kuyper (voyeurismo)? Como trabalhar esse material "bruto", essas imagens tremidas e mal enquadradas, esses planos curtos ou longos demais? Como montar tantos olhares e acenos para a câmera? Como extrair arte dessas imagens enfadonhas? Na obra do húngaro Péter Forgács, que tem como marca imprimir nas imagens amadoras os rumos da história europeia no século XX, podemos apontar, de imediato, pelos menos dois procedimentos recorrentes: trabalhar os filmes amadores como "objetos encontrados" e articular essa concepção a uma abordagem "imanente" do material registrado. Vejamos mais de perto o que isso quer dizer.

Para Forgács, tudo começa com a pergunta: "O que é um 'objeto encontrado"? (apud HABIB, 2008). O gesto dadaísta de deslocar um "objeto encontrado" do ambiente e função originais para a fabricação e montagem de um novo trabalho é, para o cineasta, fundamental. Os filmes de família e as imagens amadoras são os seus "objetos encontrados" ideais. Considerar esses acervos familiares como "objetos encontrados" significa, para Forgács, não vê-los como arquivamento do real nem como documento do que existiu, mas como imagens captadas em certas circunstâncias sociais, técnicas e políticas, atravessadas, portanto, por contextos específicos. Imagens que devem ser trabalhadas, desmontadas, remontadas, relacionadas a outros tempos, a outras imagens, a outras histórias e memórias e, ao mesmo tempo, que não devem ser vistas como ilustração de um real preexistente.

Forgács tampouco utiliza esse material como ilustração de uma ideia prévia, distanciando-se do uso mais convencional do arquivo no documentário clássico. É certamente a filiação do cineasta às artes plásticas, nos anos 70, e suas afinidades com a atitude artística do movimento Fluxus, que o afastou do uso meramente ilustrativo de imagens de arquivo. De certo modo, Forgács tem uma abordagem que poderíamos chamar de “imanente", que parte do que o material contém, e não de uma 
ideia já estabelecida ou de um conceito anterior. A singularidade do que vemos é crucial. Ele escava as imagens, descreve situações, descobre camadas, nomeia personagens: não é a toa que os nomes próprios são tão importantes - e repetidos - ao longo dos filmes, assim como a relação entre aqueles que aparecem nas imagens, a evolução dessas relações e também as circunstâncias da morte de muitos personagens. Os procedimentos estéticos que utiliza ressaltam justamente essas singularidades - além de imprimir um estilo particular aos filmes: repetição de imagens, câmera lenta, paradas na imagem, fusões, legendas, colorizações, trilha sonora. Estão lá para chamar a atenção para certos aspectos das imagens e retirar delas qualquer função ilustrativa.

No entanto, buscar uma abordagem "imanente" não significa ater-se exclusivamente ao material de um único cineasta amador - isso pode acontecer, mas não é, em absoluto, uma regra. As associações de materiais domésticos alheios, tendo como base a filmagem de um cinegrafista amador, acontecem em muitos filmes, mas Forgács retoma esse procedimento de maneira quase sempre diversa.

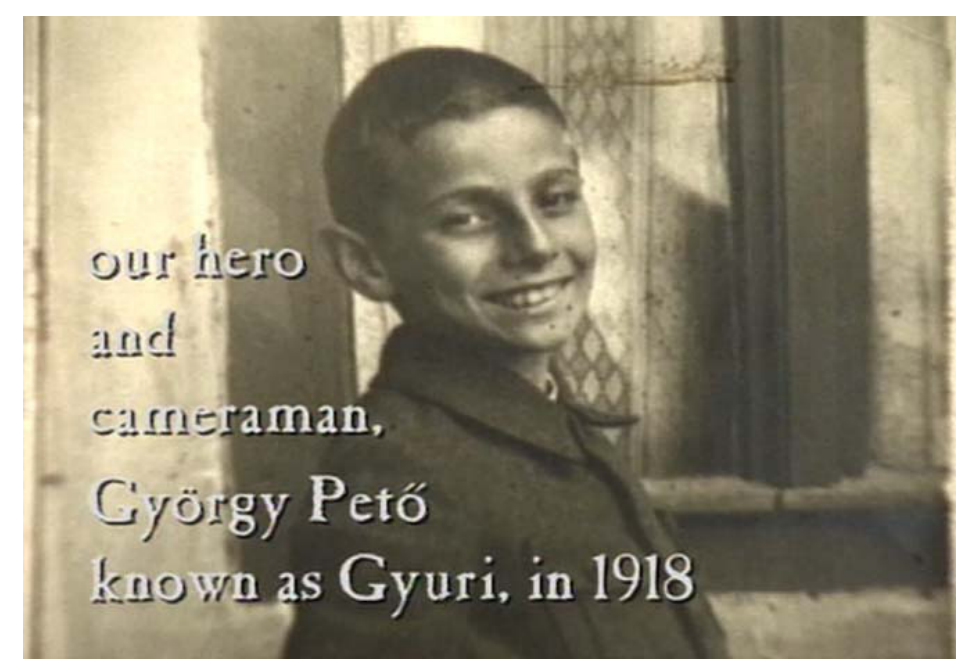



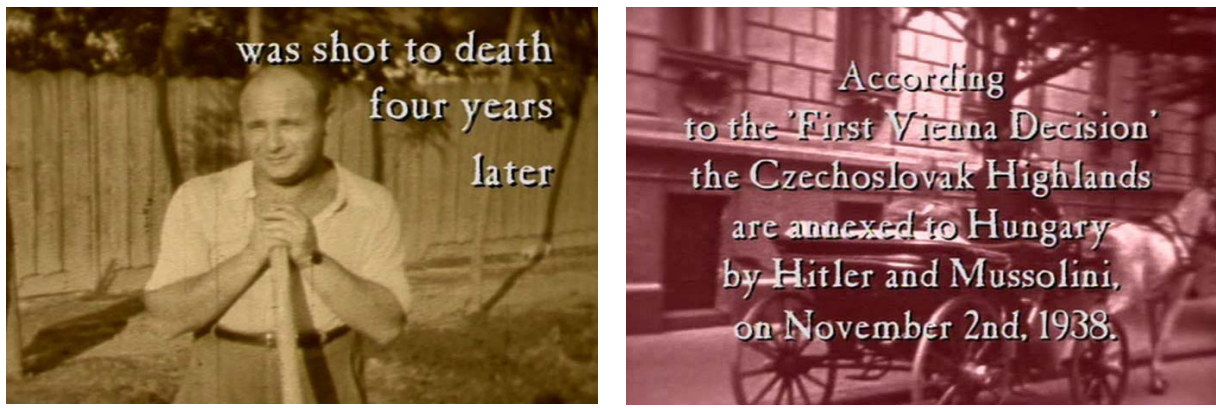

Figuras 2 e 3. Imagens de Queda livre (1996), Péter Forgács

Em Queda livre (1996), por exemplo, Forgács utiliza, na maior parte do filme, imagens produzidas pelo cinegrafista familiar György Pető, com exceção de algumas fotografias e de três notícias de jornal. Quando o filme aproxima-se do seu final, o diretor passa a inserir cinejornais de época e imagens de outros cinegrafistas. As últimas filmagens feitas por György durante a guerra mostram o cinegrafista, a esposa e o filho no quintal de uma "casa judaica" em março de 1944, mês da ocupação da Hungria pelos nazistas. Nesse filme, o contraponto entre espaço público e vida privada é criado menos pela inserção de imagens de outras fontes e mais enfaticamente pela trilha sonora, composta por diferentes narrações em off e por efeitos visuais. Sobre as imagens familiares registradas por Pető, ouvimos uma voz feminina narrando detalhadamente as leis de restrições aos judeus que foram implementadas na Hungria antes mesmo da invasão germânica: limitações ao trabalho, a atividades econômicas, ao casamento etc.

Em O turbilhão: uma crônica familiar (1997), imagens cotidianas da família Peereboom são associadas a imagens de situações domésticas envolvendo nazistas: cenas de Seyss-Inquart, administrador nomeado por Hitler para dirigir a Holanda ocupada, em família e com os amigos, em suas horas de lazer. Excetuando as sequências em que vemos homens em uniforme, são cenas bastante semelhantes, com gestos parecidos: Max e Annie Peereboom patinam em um dia de inverno, assim como a família Seyss-Inquart. Bebês e crianças são objeto de interesse nas duas famílias. 
Filmes de família, cinema amador e a memória do mundo | Consuelo Lins e Thais Blank

Figuras 4, 5 e 6. Imagens de $\mathrm{O}$ turbilhão: uma crônica familiar (1997), Péter Forgács
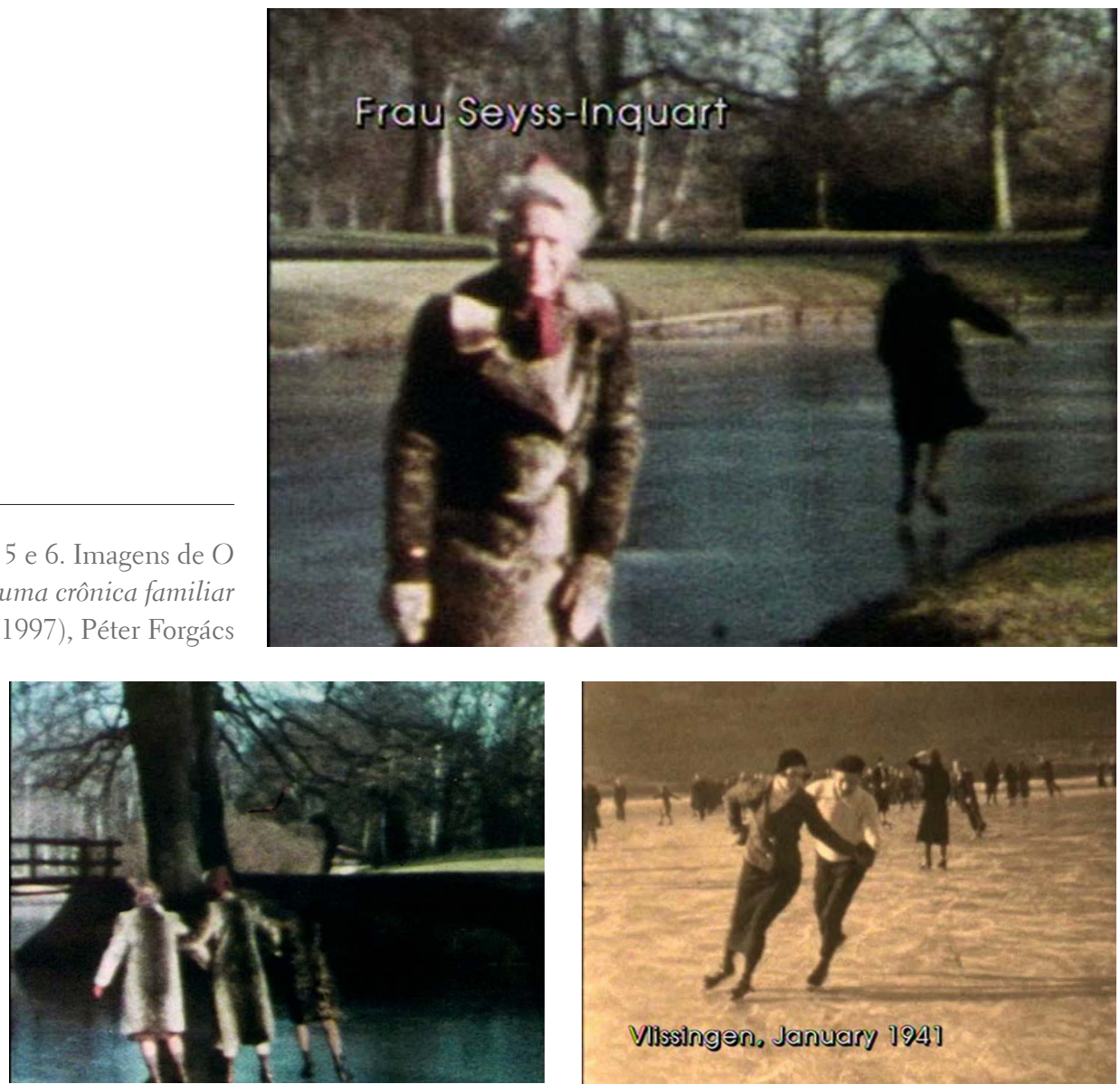

7. Arthur Seyss-Inquart foi julgado,

Em muitos momentos, nada nas imagens do líder nazista nos diz claramente que ali está um antissemita de primeira, responsável condenado e executado pelo

Tribunal de Nuremberg por crimes contra a humanidade.

8. Expressão de G. Didi-Huberman. In: Images malgré tout, p. 43. pela morte de milhares de pessoas, pela promulgação de leis de exclusão cada vez mais duras, pela implantação do estado de terror absoluto para os judeus holandeses ${ }^{7}$. Apenas a banalidade familiar cotidiana. $O$ que faz o espectador perceber as diferenças é a montagem de Forgács, mas a semelhança entre as imagens familiares reforça uma ideia central para o diretor: conceber o genocídio como uma "possibilidade humana", perpetrado por pessoas normais, com uma vida normal. Para Forgács, "só é

9. "You can only understand these

Nazi or Soviet or Cambodian criminals who led these massacres if you look at them as human possível compreender esses criminosos nazistas, mas também os soviéticos ou cambojanos que lideraram esses massacres, se você olha para eles como seres humanos capazes de fazer essas coisas". Postura que ecoa as palavras do escritor Georges Bataille, em 
beings who are capable of doing such things." Tradução das autoras.

Disponível em: $<$ http://www.rouge.com.au/12/ forgacs.html>.

Figuras 6, 7 e 8. Imagens de Miss Universo, 1929 (2006), Péter Forgács
1947: "A imagem do homem está inseparável, daqui para a frente, de uma câmera de gás" (apud DIDI-HUBERMAN, 2003, p. 42).

Essa concepção contribui para Forgács não integrar em seus filmes imagens dos campos de concentração ou de sofrimento explícito - vemos no máximo judeus obrigados a andar com a estrela amarela ou em filas de registro nos guetos. Para ele, de todo modo, as imagens da Shoah estão arquivadas na mente do espectador; não é preciso insistir nelas. O que interessa "é a estrada que leva até lá", a partir de uma visão interna do que poderia ter sido a vida das vítimas. "A cena do crime é prova suficiente", diz. Nesse sentido, ele se coloca explicitamente ao lado do cineasta Claude Lanzmann, diretor de Shoah (1985), para quem não há imagens do extermínio, e qualquer cena dos campos, ao contrário de evocar o horror, o banaliza, intensificando o que a máquina midiática de produção e difusão de imagens não cessa de fazer.

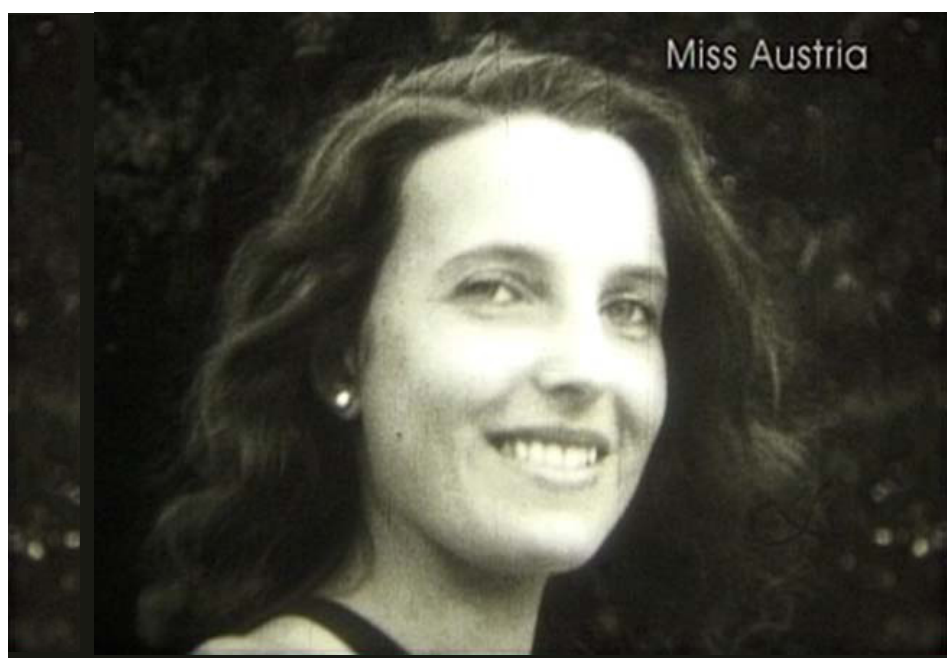

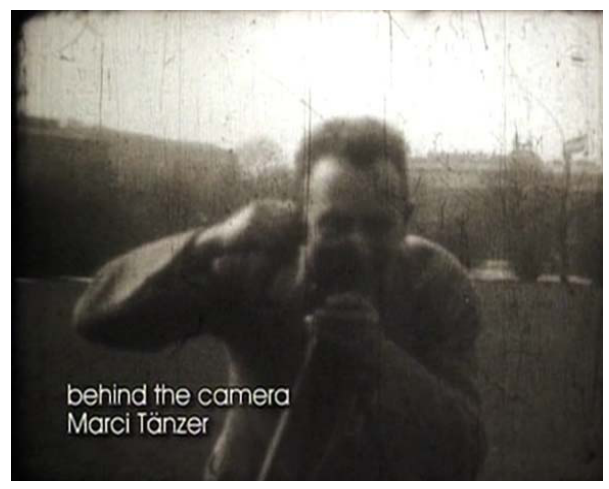

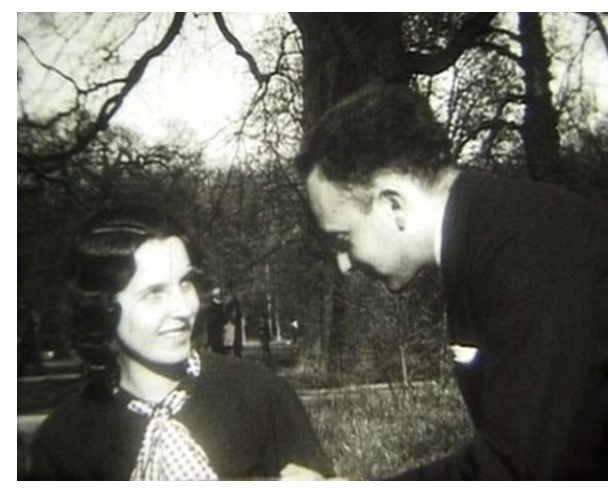


Em um filme mais recente, Miss Universo, 1929, já citado aqui, Forgács parte inicialmente das filmagens realizadas pelo húngaro Marci Tenczer a partir do final dos anos 20 e ao longo das décadas seguintes, mas as associa com muitos outros materiais: fotografias familiares ou de arquivos públicos, atualidades cinematográficas, recortes de jornal, legendas, trechos de diários, cartas, cartõespostais e uma conversa com o próprio Marci - tudo isso mesclado a uma elaborada trilha sonora. Forgács cria uma trama complexa em que a vida dos personagens e os rumos tomados por eles se confundem com o destino do mundo, estilhaçando as fronteiras entre o universo privado e a história.

O filme narra a trajetória da jovem judia austríaca Lisl Goldarbeiter, primeira europeia a receber o prêmio de Miss Universo. Apaixonado pela prima, Marci Tenczer registrou com sua Pathé Baby diversos momentos da vida da jovem de classe média que se transformou em ideal de beleza universal. A trajetória de Goldarbeiter é mostrada a partir de vestígios da sua intimidade: a fama, o amor, o casamento, as relações familiares. Ao mesmo tempo, acompanhamos a dissolução do império Austro-Húngaro, a direita ganhando força em manifestações de rua em Viena, a anexação da Áustria pela Alemanha, a invasão da Hungria. Essa outra história não está, na maior parte do tempo, nos registros produzidos por Marci, mas em um "fora de campo" que nos é dado pela montagem, nas relações criadas pelo diretor entre som e imagem.

Péter Forgács adota em Miss Universo um procedimento diferente dos encontrados em seus outros filmes. Em vez de contrapor a vida privada aos acontecimentos históricos, ele os entrelaça: a própria imagem de Lisl não pertence apenas às pessoas próximas; ela está no mundo como figura pública, e sua vida é imediatamente afetada pelos eventos que assolam a Europa. Ao contrário do que ocorre em Queda livre, a questão que inquieta o espectador em Miss Universo não é se os personagens sobreviverão ao Holocausto. Forgács não cria nenhum suspense sobre o destino final de Lisl: ainda no início do filme, ele insere uma imagem da 
personagem nos anos 80; sabemos que ela sobreviverá, assim como Marci, que é um dos narradores dessa história. O que o espectador se pergunta é como eles sobreviverão e que rumo darão às suas vidas, e se Marci conseguirá casar com Lisl depois de tantos anos de amor e dedicação a distância. Apesar da história, ainda há em Miss Universo a possibilidade de um final "feliz".

É raro, em meio à produção artística envolvendo os acontecimentos da Segunda Guerra Mundial, experimentar em uma obra tamanha proximidade com personagens reais que ignoram absolutamente que estão à beira do precipício. É raro compartilhar com tanta intensidade existências ao mesmo tempo reais, banais e trágicas. A mistura entre o que nós sabemos da história e o que os personagens filmados ainda não sabem é o que há de mais perturbador nos filmes de Forgács.

10. Didi-Huberman faz uma extensa reflexão sobre o trabalho de H. Farocki nos textos citados na bibliografia, datados de 2010.
Como extrair de memórias pessoais uma memória do mundo? Essa questão, colocada no início deste texto, não possui evidentemente resposta definitiva, dada de uma vez por todas. Os procedimentos são múltiplos e inventados a cada obra. De todo modo, um caminho possível pode estar na expressão "artista-arqueólogo", elaborada por G. Didi-Huberman, ao analisar a obra do cineasta e artista multimídia Harun Farocki ${ }^{10}$. Trata-se de um artista que se volta para os documentos da história abandonando o pensamento prévio, desarmando os olhos e reaprendendo as imagens. Para Huberman, o “artista-arqueólogo” não é em absoluto um nostálgico voltado para o passado: é um indivíduo que “abre” os tempos das imagens e dos documentos, atento às singularidades dos materiais no ato mesmo de construir suas montagens. Péter Forgács procede, a nosso ver, do mesmo modo, ao se voltar para o passado, reconstruindo sentidos de imagens que não são mais que vestígios de um projeto familiar, de uma experiência de vida. Escava ruínas da intimidade, descobre nelas elementos latentes que não eram visíveis à época de sua captação, extraindo dos pequenos dramas 
individuais os destinos de uma época. O espectador é capturado nas suas emoções, identificando-se com narrativas e personagens jogados à revelia nas tragédias do século XX - uma empatia que não perde de vista uma distância crítica. Podemos pensar então que os cineastas que escavam imagens tal qual um arqueólogo estão determinados a aguçar os sentidos do espectador, a abrir seus olhos, a fazê-lo ver documentos do passado de formas novas e a torná-lo mais apto a decifrar por conta própria a ligação entre as imagens e a violência do mundo. Nem sempre com o talento de Péter Forgács. 


\section{Referências}

AASMAN, S. "Le film de famille comme document historique". In: ODIN, R. (Ed.). Le film de famille: usage privé, usage public. Paris: Méridiens Klincksieck, 1995.

ALLARD, L. "L' amateur: une figure de la modernité esthétique". Communications, Paris, 68, 1999.

CATALÀ, J. M. "Las cinizas de Pasolini y el archivo que piensa”. In: WEINRICHTER, A. (Dir.). La forma que piensa: tentativas en torno al cine-ensaio. Navarra: Gobierno de Navarra, 2007.

DIDI-HUBERMAN, G. Images malgré tout. Paris: Les Éditions de Minuit, 2003.

L'oeil de l'histoire: remontages du temps subi T2. Paris: Les Éditions de Minuit, 2010.

"Remonter, refrendre, restituer". In: CRIQUI, J. (Dir.). L'image-document entre realité et fiction. Paris: Images en Manoeuvres Éditions: Le Bal; Marseille: Images en Manoeuvres Éditions, 2010.

ESCOREL, E. "Camadas ocultas". In: FORGÁCS, P. Arquitetura da memória. São Paulo: [s.n.], 2012.

ESQUENAZI, J. "L'effet 'film de famille". In: ODIN, R. (Ed.). Le film de famille: usage privé, usage public. Paris: Méridiens Klincksieck, 1995.

FOSTER, L. Filmes domésticos: uma abordagem a partir do acervo da Cinemateca Brasileira. Dissertação (Mestrado) - Universidade Federal de São Carlos, São Carlos, 2010.

HABIB, A. "It's just a waste of time to walk and play tennis". Entrevista com Péter Forgács, 2008. Disponível em: <http://www. Forgácspeter.hu/english $>$.

JOURNOT, M. Films amateurs dans le cinéma de fiction. Paris: Armand Colin, 2011.

KUYPER, E. de. "Aux origines du cinéma: le film de famille". In: ODIN, R. (Ed.). Le film de famille: usage privé, usage public. Paris: Méridiens Klincksieck, 1995. 
LE GALL, L. "Films amateurs et sociétés littorales dans la Bretagne des années 1920 et 1930". Annales de Bretagne et des pays de l'Ouest, Rennes, n. 117-3, p. 127-152, 2010.

LINDEPERG, S. “Le film palimpseste”. In: DOC'S KINGDOM, SEMINÁRIO INTERNACIONAL SOBRE CINEMA DOCUMENTAL, 2008, Serpa (Portugal). Paisagens: o trabalho do tempo.

Nuit et brouillard: un film dans l'histoire. Paris: Odile

Jacob, 2007.

LINS, C; BLANK, T. "Ruínas da intimidade: os objetos encontrados por Péter Forgács”. In: FORGÁCS, P. Arquitetura da memória. São Paulo: [s.n.], 2012.

NICHOLS, B. Cinema's alchemist: the films of Peter Forgács. Minessota: University of Minnesota, 2012.

ODIN, R. "As produções familiares de cinema e vídeo na era do vídeo e da televisão". Cadernos de Antropologia e Imagem, 17, Rio de Janeiro, 2003.

"La question de l'amateur dans trois espaces de réalisation et de diffusion”. Communications, Paris, 68, p. 47-89, 1999.

"Le film de famille dans l'institution familiale". In:

ODIN, R. (Ed.). Le film de famille: usage privé, usage public. Paris: Méridiens Klincksieck, 1995.

RANCIÈRE, J. A partilha do sensível: ética e política. Rio de Janeiro: 34, 2005.

SIEREK, K. “C'est beau, ici'. Se regarder voir dans le film de famille”. In: ODIN, R. (Ed.). Le film de famille: usage privé, usage public. Paris: Méridiens Klincksieck, 1995.

ZIMMERMANN, P. Mining the home movie: excavations in histories and memories. Berkeley: University of California, 2008.

- Reel families: a social history of amateur film. Bloomington: Indiana University, 1995. 